\title{
OPTIMASI EKSTRAKSI ASAM HUMAT DARI Na-HUMAT DAN KARAKTERISASINYA DENGAN FTIR
}

\author{
Muzakky, Agus Taftazani dan Sukirno \\ Puslitbang Teknologi Maju BATAN. Yogyakarta
}

\begin{abstract}
ABSTRAK
OPTIMASI EKSTRAKSI ASAM HUMAT DARI Na-HUMAT DAN KARAKTERISASINYA DENGAN FTIR. Telah dilakukan optimasi ekstraksi asam humat dari Na-humat dan karakterisasinya dengan FTIR. Tujuan penelitian ini untuk isolasi asam humat dari tanah gambut dengan metoda ekstraksi cair-cair. Sebagai umpan Na-humat, dibuat dengan mereaksikan tanah gambut ukuran 400 mesh dengan $\mathrm{NaOH}$ 0,1 N selama 24 jam. Ekstraktan dipilih "metil iso butil keton" (MIBK) karena cukup selektif terhadap asam humat, sedangkan karakterisasinya menggunakan "fourier transform infra red" (FITR). Hasil ekstrasi optimum pada waktu kontak 15 menit, konsentrasi fasa organik MIBK $80 \%$ dan $\mathrm{pH}$ 3. Hasil karakterisasi FTIR ternyata menghasilkan munculnya spektra IR pada daerah $3442,7 \mathrm{~cm}^{-1}$, 2922.0 dan $2852.5 \mathrm{~cm}^{-1}, 1716,5 \mathrm{~cm}^{-1}$ serta $1624.0 \mathrm{~cm}^{-1}$. Hal ini berarti bahwa karakreristik asam humat hasil ekstraksi tidak berbeda jauh dengan asam humat standar. Tetapi dengan munculnya spektra pada pita $1120.7 \mathrm{~cm}^{-1}$ dan banyaknya spektra pita-pita diatas $3500 \mathrm{~cm}^{-1}$ asam humat hasil ekstraksi belum bebas dari $\mathrm{SiO}_{2}$ dan pengotor logam.
\end{abstract}

Kata kunci : Asam humat, Na-Humat. FTIR, MIBK.

\section{ABSTRACT}

OPTIMIZATION EXTRACTION OF HUMIC ACID FROM Na-HUMATE AND CHARACTERIZATION BY FTIR. The Optimization extraction of humic acid from Na-Humate and characterization by FTIR has been done. For that purpose, the study is to isolate of humic acid from peat soil. by liquid-liquid extraction. As a feed the Na-humate was made by reaction of 400-mesh size of peat soil with $0.1 \mathrm{~N} \mathrm{NaOH}$ during 24 hour. The extracted was using by methyl iso butyl ketone (MBIK) because it's very' selected with humic acid, while Fourier Transform Infra 'Red. (FITR) for characterization. The result of extraction were optimize at 15 minute, $80 \%$ MIBK concentration and $p H$ 3. The result of characterization by FTIR, appeared of spectra on $3442.7 \mathrm{~cm}^{-1}, 2922.0$ and 2852.5 $\mathrm{cm}^{-1}, 1716,5 \mathrm{~cm}^{-1}$ also on $1624.0 \mathrm{~cm}^{-1}$. Its mean that characterized of extraction result was significant by humic acid standard. But appeared spectra on $1120.7 \mathrm{~cm}^{-1}$ and upper $3500 \mathrm{~cm}^{-1}$ humic acid extraction result not free from $\mathrm{SiO}_{2}$ and metals impurities.

Keyword: humic acid. Na-Humate, FTIR, MIBK.

\section{PENDAHULUAN}

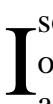
solasi senyawaan humik dari tanah organik teIah dimulai pada tahun 1930an, para peneliti mulai menggunakan larutan garam netral dari asam-asam mineral dan juga garam-garam oksalat serta asamasam organik lain dengan berat molekular rendah. Pada perkembangan selanjutnya, berbagai pelarut organik dan anorganik digunakan untuk mengisolasi senyawaan humik dari tanah organik ${ }^{(\mathrm{l})}$.
Perhatian besar diberikan untuk garamgaram netral dari asam-asam mineral, khususnya natrium pirofosfat. Pada awalnya garam netral ini banyak digunakan untuk mengisolasi asam humat dari tanah organik. Namun demikian sejumlah penulis dalam penelitian-penelitian yang sama telah melaporkan bahwa larutan tersebut hanya sedikit mengekstrak substansi-substansi senyawa humik dari tanah organik, dibandingkan dengan larutan alkali. Larutan $\mathrm{NaOH} \quad 0,1 \quad \mathrm{M}$ diketahui sangat efektif 
mengekstrak senyawaan humik, dimana senyawaan humik larut dalam $\mathrm{NaOH}$ sedangkan humin dan senyawa bukan humik lainnya tidak larut ${ }^{(2)}$. Untuk mendapatkan asam humat dari larutan $\mathrm{NaOH}$ ini perlu ditambahkan $\mathrm{HCl}$ dan pengaturan $\mathrm{pH}$ hingga 2 sehingga asam humat akan menggumpal dan tidak larut, sedangkan asam fulfat tetap larut. Asam humat selanjutnya dipisahkan dari larutan basa asam fulfat dengan jalan pemusingan berulang-ulang dan memerlukan waktu lama. Asam humat yang telah dipisahkan ini selanjutnya masih harus dikering bekukan agar diperoleh asam humat kering $^{(3)}$. Cara isolasi ini merupakan cara klasik, sehingga untuk memperoleh asam humat tcrsebut akan memerlukan waktu lama dan hasil perolehan yang rendah.

Dengan demikian rumit, dan lama dalam mengisolasi asam humat tersebut di atas, maka pada penelitian ini dicoba cara lain dengan metoda ekstraksi cair-cair menggunakan pelarut organik metil isobutil keton (MIBK) ${ }^{(4)}$. Alasan dipilihnya MIBK menurut Stcvenson ${ }^{(6)}$ dapat dilihat pada tabel 1 .

Tabel 1. Perolehan asam humat dari tanah

\begin{tabular}{|c|l|c|c||}
\hline $\begin{array}{c}\text { Kedalaman } \\
(\mathrm{m})\end{array}$ & $\begin{array}{c}\text { Senyawa } \\
\text { terisolasi }\end{array}$ & $\begin{array}{c}\text { Metoda klasik } \\
(\mathrm{NaOH}) \mathrm{g} / 100 \\
\mathrm{~g} \text { gambut }\end{array}$ & $\begin{array}{c}\text { Metoda } \\
\text { ekstraksi } \\
\text { MIBK g/100 g } \\
\text { gambut }\end{array}$ \\
\hline $0,1-1$ & Asam humat & 6,0 & 6,2 \\
& Asam fulvat & 0,76 & 10,0 \\
Humin $-2,0$ & - & 4,2 \\
& Asam humat & 6,0 & 14,0 \\
& Asam fulvat & 0,54 & 3,8 \\
Humin & - & 7,0 \\
\hline
\end{tabular}

\section{Teori}

Secara sederhana ekstraksi asam humat (A) dengan MIBK (Ox) dapat dinyatakan sebagai berikut,

$$
\mathrm{An}^{+1}+\mathrm{nOx}^{-} \Leftarrow \mathrm{AOxn}
$$

$\mathrm{KAOxn}=\frac{[\mathrm{AOxn}]}{\left[\mathrm{An}^{+1}\right]\left[\mathrm{Ox}^{-}\right]}$

Disosiasi dari ekstraktan MIBK adalah , $\mathrm{HOx}^{+} \Leftarrow \Rightarrow \mathrm{H}^{+}+\mathrm{Ox}^{-}$,
$\mathrm{Ka}=\frac{\left[\mathrm{H}^{+}\right]\left[\mathrm{Ox}^{-}\right]}{[\mathrm{HOx}]}$

Distribusi ekstraktan diantara fase air (fa) ke fase organik (fo),

$[\mathrm{HOx}]_{\mathrm{a}} \Leftarrow \Rightarrow[\mathrm{HOx}]_{\mathrm{o}}$,

$\mathrm{Kd}=\frac{[\mathrm{HOx}]_{\mathrm{O}}}{[\mathrm{HOx}]_{\mathrm{a}}}$

Notasi subskrip (a) merupakan fase air dan (0) adalah fase organik, dengan demikian distribusi kompleks senyawa humat dalam ke dua fase adalah,

$[\mathrm{AOx}]_{\mathrm{a}} \Leftarrow \Rightarrow[\mathrm{AOx}]_{\mathrm{o}}$

$\mathrm{K}_{\mathrm{d}}^{1}=\frac{\left[\mathrm{AOx}_{\mathrm{n}}\right]_{\mathrm{O}}}{\left[\mathrm{AOx}_{\mathrm{n}}\right]_{\mathrm{a}}}$

Dengan asumsi bahwa hanya [AOxn] yang ada dalam fase organik dan $\mathrm{A}^{\mathrm{n}+}$ terdapat dalam fase air, maka koefisien distribusi (KD) adalah,

$\mathrm{KD}=\frac{\left[\mathrm{AOx}_{\mathrm{n}}\right]_{\mathrm{O}}}{\left[\mathrm{A}^{\mathrm{n}+}\right]_{\mathrm{a}}}$

Menurut Hirano,T.S ${ }^{(7)}$ substitusi persamaan (1), (2), (3) dan (4) kedalam persamaan (5), akan kita dapatkan,

$\mathrm{KD}=\frac{\mathrm{K}_{\mathrm{AO}_{\mathrm{n}}} \mathrm{K}_{\mathrm{d}} \mathrm{K}_{\mathrm{a}}^{\mathrm{n}}}{\left(\mathrm{K}_{\mathrm{d}}^{1}\right)^{\mathrm{n}}} \cdot \frac{[\mathrm{HOx}]_{\mathrm{O}}^{\mathrm{n}}}{\left[\mathrm{H}^{+}\right]_{\mathrm{a}}^{\mathrm{n}}}$

Kita sederhanakan persamaan (6) dengan mengambil sebagian harga persamaan tersebut,

$\frac{\mathrm{K}_{\mathrm{AOx}_{\mathrm{n}}} \mathrm{K}_{\mathrm{d}} \mathrm{K}_{\mathrm{a}}^{\mathrm{n}}}{\left(\mathrm{K}_{\mathrm{d}}^{1}\right)^{\mathrm{n}}}=\mathrm{K}_{\mathrm{ex}}$

Sehingga penyederhanaan persamaan (6) diatas menjadi,

$\operatorname{logKD}=\log \mathrm{K}_{\mathrm{ex}}+\mathrm{nlog}[\mathrm{HOx}]_{\mathrm{o}}+\mathrm{n} \cdot \mathrm{pH},(8)$

\section{TATA KERJA}

\section{Bahan-bahan}

Tanah gambut yang diambil dari Kalimantan, $\mathrm{NaOH}, \mathrm{KOH}, \mathrm{Na}_{2} \mathrm{CO}_{3}$, KCI dan 
HCI, dan ekstraktan Metil Isobutil Keton (MIBK), Kerosin, N-N-dimethylacetamida semuanya buatan E. Merck.

\section{Alat-alat}

Seperangkat Spektrometer UV-Visible, HEWLETT 8452 A PACKARD Diode Array Spectrophotometer, seperangkat alat FTIR, corong pisah $500 \mathrm{ml}$, pengaduk magnet dan alat pemusing.

\section{Cara kerja}

1. Pembuatan larutan umpan Na-humat ${ }^{(8)}$

Diambil tanah gambut kcring dengan ukuran butiran 400 mesh, dengan berat 0,1 gram ke dalam crlenmeycr $50 \mathrm{ml}$ dan ditambahkan 15 ml larutan $\mathrm{NaOH} 0.1 \mathrm{~N}$, sclanjutnya aduk sclama 24 jam menggunakan pengaduk magnet. Dipisahkan antara fraksi padat dengan fraksi cair menggunakan alat pemusing dengan kecepatan 2000-3000 rpm, selanjutnya fraksi larutan ditampung ke dalam wadah plastik yang selanjutnya digunakan sebagai umpan ekstraksi.

2. Ekstraksi asam/tumat dengan MIBK.

Diambil $10 \mathrm{ml}$ umpan Na-Humat dan dimasukkan ke dalam corong pisah dengan kapasitas $30 \mathrm{~m} 1$ yang didalamnya telah ada larutan $10 \mathrm{ml}$ MIBK-Kerosin 10\% (atau divariasi). Kemudian dilakukan pengocokan selama 15 menit (atau divariasi). Setelah kedua fasa terpisah kemudian diambil fasa air yang mengandung asam fulvat, dan fasa organiknya yang tinggal didalam corong pisah ditambahkan $\mathrm{NaOH} 0,1 \mathrm{~N}$ dan 0,01 gram kristal $\mathrm{KCl}$ anhidrous ${ }^{(4)}$. Kemudian dikocok kembali selama 15 menit. Setelah kedua fasa terpisah kemudian diambil fasa air yang mengandung asam humat pada wadah platik $25 \mathrm{ml}$. Diasamkan dengan $\mathrm{HCl}$ pekat hingga larutan keruh, kemudian diekstraksi dengan MIBK kembali, sehingga diperoleh asam humat dalam bentuk gel dan dikeringkan untuk dikarakterisasi menggunakan FTIR. Fasa organiknya di analisis asam humatnya dengan spektrofometer
UV-Vis pada panjang gelombang $400 \mathrm{~nm}$ dan N, N-Dimetilasetamida sebagai pengencer dengan perbandingan volume sebesar $1: 1$.

\section{HASIL DAN PEMBAHASAN}

Hasil dan pembahasan ini kita awali terlebih dahulu dengan menentukan optimasi waktu kontak, atau waktu reaksi dari persamaan (1) serta reaksi kesetimbangan dari persamaan (2), (3) dan (4) menjadi sempuma. Dari Gambar 1, dapat diperlihatkan proses waktu kontak semakin lama, akan menjadi stabil atau konstan. Atau dengan kata lain KD asam humat dari larutan Na-humat kepelarut organik MIBK semakin besar dengan semakin lamanya waktu kontak.

Terlihat dari Gambar 1, bahwa pada menit ke-2 sampai menit ke-10 terjadi kenaikan tajam terhadap $\mathrm{KD}$ kemudian relatif stabil pada menit ke 15 yang berarti semakin banyak asam humat yang terekstrak oleh MIBK. Hal ini karena terjadinya kenaikan solvasi oleh MIBK terhadap asam humat dengan adanya kenaikan waktu kontak antar pelarut. Tanpa adanya pengocokan, pelarut MIBK akan sulit mengambil asam humat karena MIBK tidak bercampur dengan air. Dengan adanya pengocokan tersebut akan menambah kesempatan asam humat untuk berdistribusi dalam pelarut organik sehingga MIBK lebih mudah mensolvasi dan mengekstraksi dari fasa air.

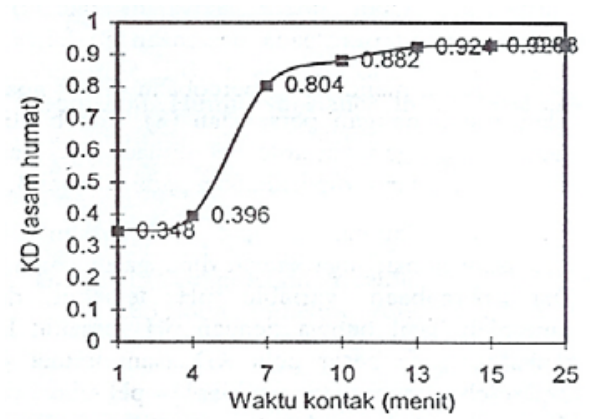

Gambar 1. Pengaruh waktu kontak terhadap KD asam humat 
Pada menit ke-15 ke atas hasil yang diperoleh relatif konstan, yang berarti bahwa penambahan waktu pengocokan tidak akan memberikan penambahan hasil yang berarti. Hal ini menunjukkan bahwa waktu pengocokan kurang lebih 15 menit merupakan waktu optimum untuk mengekstrak asam humat dengan MIBK, dan Hal ini berarti kesetimbangan pada persamaan (2), (3) dan (4) telah optimal.

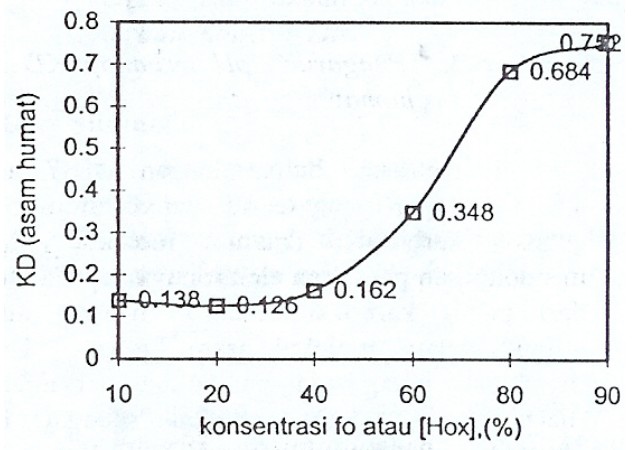

Gambar 2. Pengaruh konsentrasi \{HG.J 。 terhadap KD asam humat

Pada variable konsentrasi fasa organik $\left([\mathrm{HOx}]_{0}\right)$ terhadap $\mathrm{KD}$ asam humat, yang sesuai dengan persamaan (8) diatas bahwa $\log \mathrm{KD}$ akan merupakan fungsi konsentrasi fo $\left([\mathrm{HOx}]_{0}\right)$. Dari hasil percobaan yang diperoleh pada Gambar 2, menunjukkan bahwa semakin tinggi konsentrasi MIBK dalam kerosin, maka akan semakin besar KD asam humat.

Dari Gambar 2, tersebut tampak bahwa pada konsentrasi MIBK yang rendah $\mathrm{KD}$ asam humat akan cenderung kecil, dan pada kondisi konsentrasi MIBK yang tinggi KD asam humat akan naik. Kenaikan tertinggi dicapai pada keadaan konscntrasi $80 \%$, kcmudian relatif konstan pada konstrasi 90\%. Dcngan demikian percobaan pada Gambar 2, telah tidak menyalahi phenomena ekstraksi yang tertera pada pesamaan (8) diatas.

Untuk mendukung percobaan diatas apakah telah sesuai dengan persamaan (8), kita buktikan kembali dengan variable $\mathrm{pH}$ terhadap KD asam humat, yang dapat diperlihatkan pada gambar 3 .

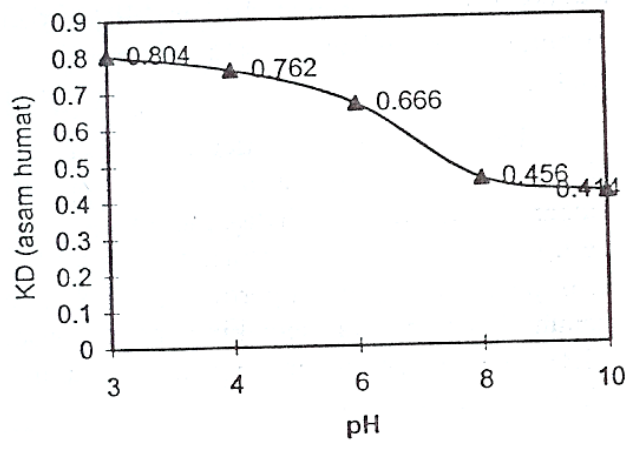

Gambar 3. Pengaruh pH terhadap KD asam humat

Dari Gambar 3, dapat diperlihatkan bahwa KD asam humat juga sangat dipengaruhi oleh $\mathrm{pH}$. Dari percobaan variable $\mathrm{pH}$ tersebut dapat diperoleh hasil bahwa dengan $\mathrm{pH}$ semakin kecil maka semakin besar pula KD asam humat yang diperoleh. Phenomena variable $\mathrm{pH}$ ini dapat diterangkan bahwa, dengan semakin tingginya $\mathrm{pH}$ maka senyawa humat akan lebih mudah terionkan dan akan lebih mudah bereaksi dengan $\mathrm{NaOH}$ membentuk Na-humat, sedangkan dalam kondisi $\mathrm{pH}$ yang semakin rendah, senyawa humat akan semakin banyak dalam bentuk tak terionkan sehingga asam humat yang terekstrak oleh MIBK akan semakin banyak

Ikatan asam humat dengan MIBK adalah ikatan hidrogen yang terjadi karena atom 0 dari gugus karbonil dalam molekul MIBK mendonorkan pasangan elektronnya kepada atom $\mathrm{H}$ dari gugus karboksil, fenolik maupun alkohol alifatik dalam molekul asam humat. Dengan demikian lengkap sudah pembuktian persamaan (8) diatas, bahwa KD ekstraksi sebagai fungsi konsentrasi fasa organik dan $\mathrm{pH}$.

Hasil akhir ekstraksi asam humat setelah melalui proses pendinginan kering, kemudian struktur gugus fungsional molekulnya dianalisis dengan alat FTIR dan hasilnya dapat ditampilkan pada Gambar 4. 
Berdasarkan hasil analisis dengan spektra FTIR scbagaimana diberikan pada gambar 4, diketahui bahwa bahan hasil ekstraksi dari tanah gambut monggunakan MIBK mcnunjukkan pola yang sama dcngan struktur asam humat standar (gambar 5). Dari spektra tersebut muncul pita-ptta utama yang merupakan karakteristik dari spektra asam humat. Pitapita tersebut muncul pada daerah 3442,7 $\mathrm{cm}^{-1}$ dengan absorpsi kuat menunjukkan bahwa pada daerah ini terjadi serapan rentang $(-\mathrm{OH})$. Namun tidak menutup kemungkinan bahwa pada daerah ini juga terdapat rentang $(-\mathrm{N}-\mathrm{H})$ dan ikatan hidrogen. Terjadinya serapan rentang $(-\mathrm{OH})$ tersebut merupakan karakteristik senyawa humat karena adanya gugus fungsional fenolik (-OH) dan alkoholik (-OH).

Pita karakteristik lain yang menunjukkan bahwa cuplikan hasil ekstraksi tersebut adalah asam humat yaitu pita serapan pada 2922.0 dan $2852.5 \mathrm{~cm}^{-1}$, pita ini terlihat sangat signifikan pada asam humat. Pita ini dapat berupa rentang vibrasi yang asimetri maupun simetri khususnya pada rentang alifatis $(\mathrm{C}-\mathrm{H})$ dalam gugus metil dan atau metilen aktif yang biasanya dalam bentuk keton terkonjugasi dengan struktur sebagai (CO-CH$\left.{ }_{2}-\mathrm{CO}-\right)$.

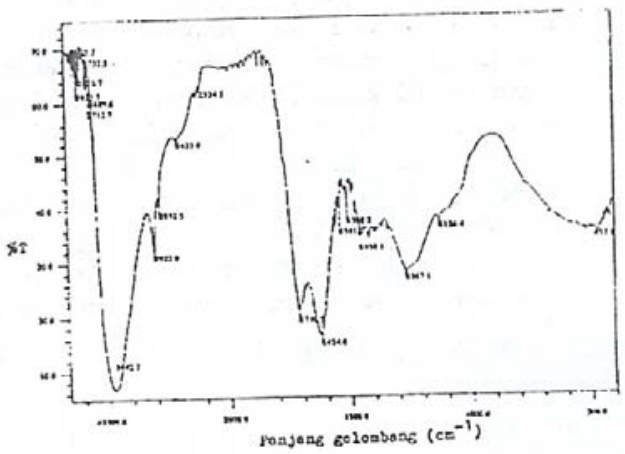

Gambar 4. Karakterisasi spektra asam humat hasil ekstrasi dengan FTIR

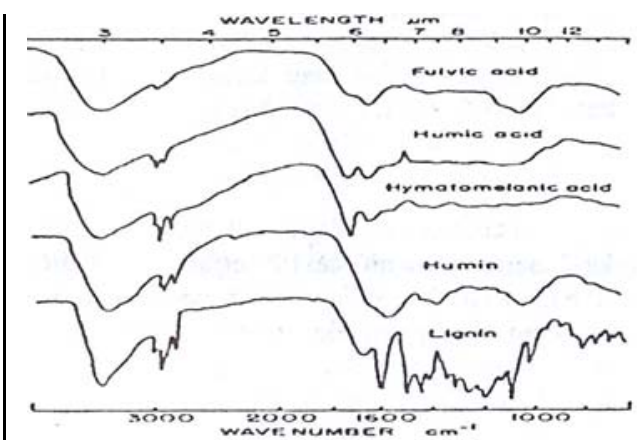

Gambar 5. Spektra FTIR asam humat dan derivatnya menurut TAN.KH. ${ }^{(3)}$

Scrapan pita $1716,5 \mathrm{~cm}^{-1}$ menandakan adanya rentang vibrasi $(\mathrm{C}=\mathrm{O})$ yang juga merupakan salah satu karakteristik spektra infra merah senyawa humat dan vibrasi $(\mathrm{C}=\mathrm{O})$ ini dapat berasal dari gugus keton, karboksilat maupun kuinon.

Pita di daerah $1624.0 \quad \mathrm{~cm}^{-1}$ menunjukkan adanya gugus aromatis $(\mathrm{C}=\mathrm{C})$ ikatan rangkap terkonjugasi dengan $(\mathrm{C}=\mathrm{O})$ dan atau (COO). Untuk pita-pita 1458,1 1541,0 dan 1508,2 cm-1 ini menandakan adanya garam dari $\mathrm{COOH}$, dimana pita ini muncul karena adanya pengotor dari clay yang ditunjukkan oleh pita-pita pada daerah $1267,2 \mathrm{~cm}^{-1}$ memperkuat adanya ikatan vibrasi alifatis gugus (C-H). Asam humat hasil ekstraksi ini rnasih mengandung pengotor $\mathrm{SiO}_{2}$ yang ditandai dengan munculnya pita pada daerah $1126,4 \mathrm{~cm}^{-1}$. Perbedaan yang jelas dari. gambar 4 dengan 5 adalah masih adanya pengotor dari asam humat yang diperoleh dari ekstraksi cair-cair menggunakan MIBK.

\section{KESIMPULAN}

Asam humat dapat di ekstrasi dari Nahumat, dengan cara ekstraksi cair-cair menggunakan MIBK. Kondisi optimum ekstraksi dilakukan pada waktu kontak 15 menit, konsentrasi fasa organik MIBK 80\% dan $\mathrm{pH}$ 3. Dengan munculnya spektra IR pada daerah 3442,7 cm $\mathrm{cm}^{-1}, 2922.0$ dan 2852.5 $\mathrm{cm}^{-1}, 1716,5 \mathrm{~cm}^{-1}$ serta $1624.0 \mathrm{~cm}^{-1}$, berarti karakteristik asam humat hasil ekstraksi 
tidak berbeda jauh dengan asam humat standar. Tetapi dengan munculnya pita $1120.7 \mathrm{~cm}^{-1}$ dan banyaknya pita diatas 3500 $\mathrm{cm}^{-1}$ asam hasil ekstraksi belum bebas dari $\mathrm{SiO}_{2}$ dan pengotor logam

\section{DAFTAR PUSTAKA}

1. Kononova.M.M., Soil organic matter, It's nature, It's role in soil formation and in soil fertility., London, second edition, Pergamon Press., 1966.

2. Aiken.,G.R et aI., An Introduction to humic substance in soil, sedimen, and water : Geochemistry, isolation and characterisation, Wiley-Interscience, New York., 1985.

3. TAN.K.H., Soi Sampling, Preparation, and Analysis , Marcel Dekker,Inc, New York, (1996).

4. Rice.,J., and Maccarthy.P, Isolation of humin by liquid-liquid partitioning., The science of the total environment., 81/82., p.61-63.
5. Elsevier Science publishers., Amsterdam., ( 1989).

6. Hayes,M.H.B., Extraction of humic substances from soil, Humic substance in soil, sediment and water geochemistry, Isolation and characterization, WileyInterscience, New York, (1995).

7. Stevenson, F.J., "Humus Chemistry", Genesisi, Composition, Reaction , $2^{\mathrm{Ed}}$., John Wiley and Soon., Inc.New york., (1982).

8. Hirano, T.S et all., The Physic-chemical behavior of radioactive cerium in seawater., Radioactive contamination of the marine environment., Proceeding of a symposium Seattle, IAEA, Vienna, (1972).

9. Muzakky, AgusTanazani, Sumining, Optimasi reaksi tanah gambut dengan basa sodium pada sistim catu., Prosiding PPI-PDIPTN P3TMBATAN Yogyakarta, (2002). 